\title{
The persunfate oxidation of fulvic acids
}

\section{F. Martin and F.J. Gomzalez-Vila}

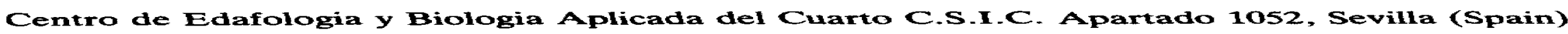

\section{Summmary - Zusammmemfasabug}

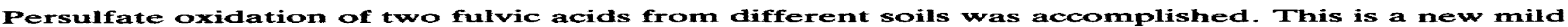

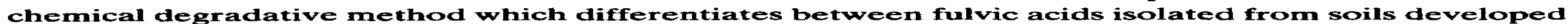

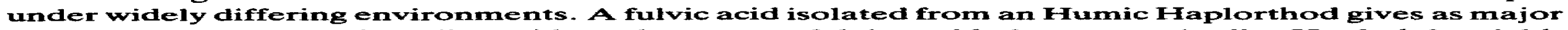

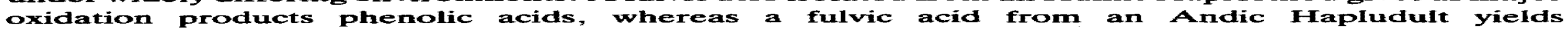

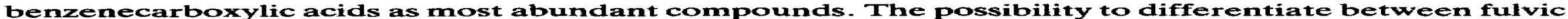

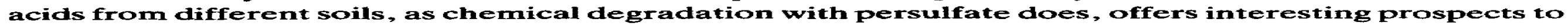
the characterization of humic materials.

Abban vom Fulvosänem mît kaliumpersulfat

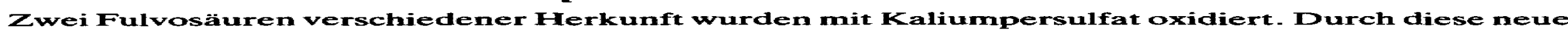

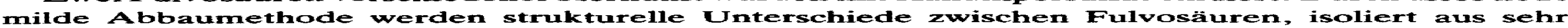

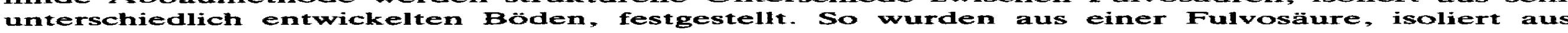

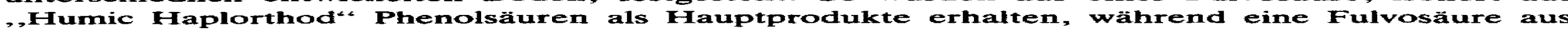

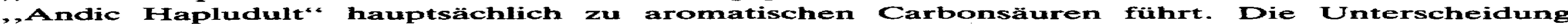

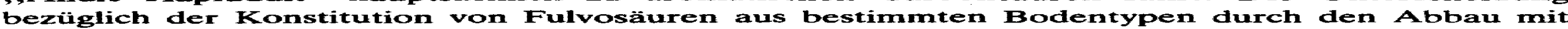
Kaliumpersulfat bietet eine Möglichkeit zur Fuminstoff-Charakterisierumg.

\section{Introdaction}

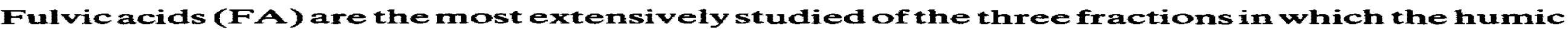

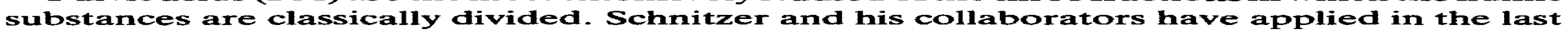

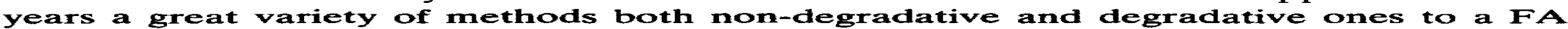

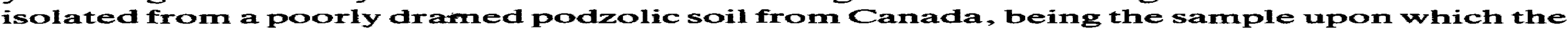
"building block" model of humic substances is based.

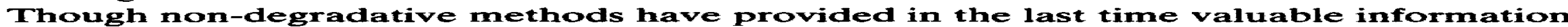

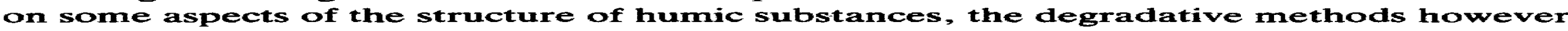

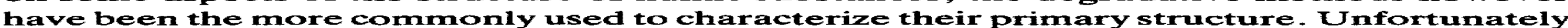

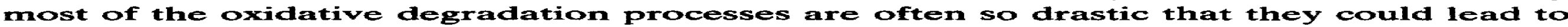

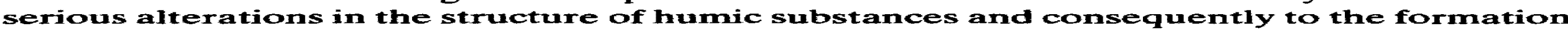

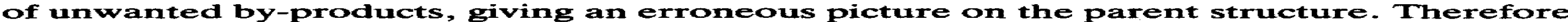

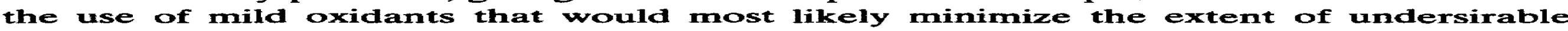
modifications seems worthwhile of investigation.

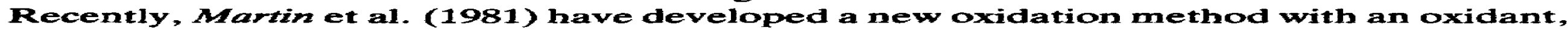

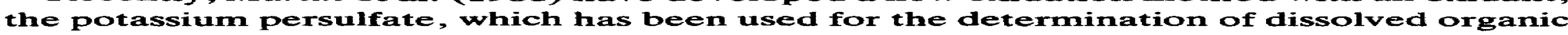


carbon in seawater. When applied to humic acids (IA) only $40 \%$ of the starting material degrades leaving a residue that can easily be recovered for further structural investigations. As persulfate has become a mild degradative oxidation method at acid pFI, we thought it would be interesting to apply it to FA from two different soil types, in order to evaluate the potential ability of this method for FA's structural studies.

\section{Materials and Methods}

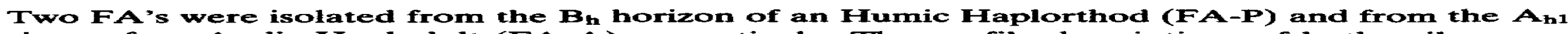

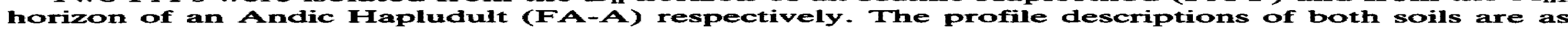
follows:

Classification

Location

Elevation

Topography

Orientation

Parent material

Vegetation

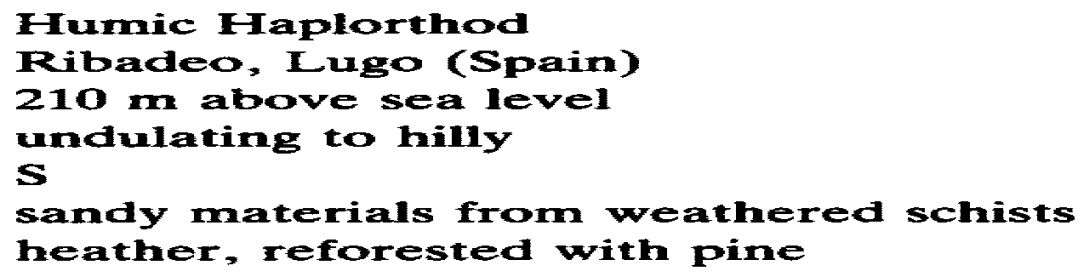

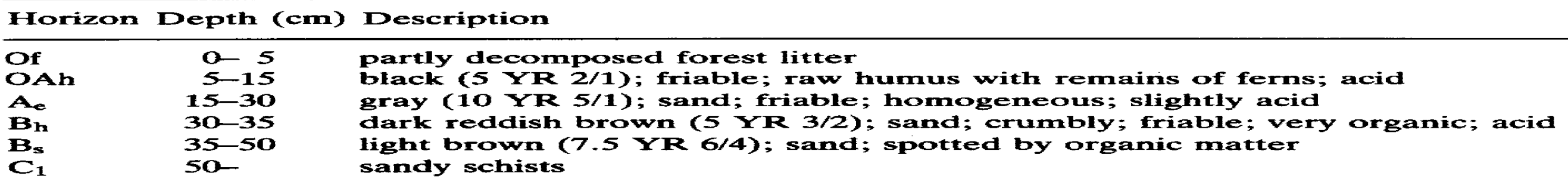

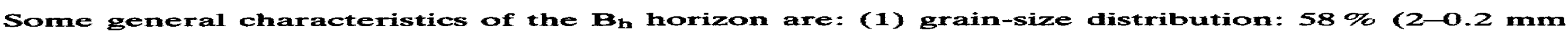

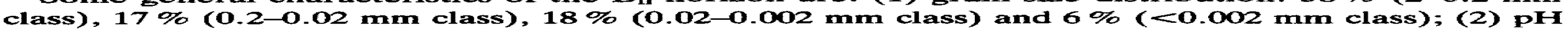
$\left(\mathrm{F}_{2} \mathrm{O}\right)=3.3 ;$ and $(3) C$-content $=6.6 \%$.

Classification

Location

Elevation

Topography

Orientation

Parent material

Vegetation
Andic Fapludult

Tenerife Island, Spair

$400 \mathrm{~m}$

highly undulating

NW

basalt

laurisilva

Horizon Depth (cm) Description

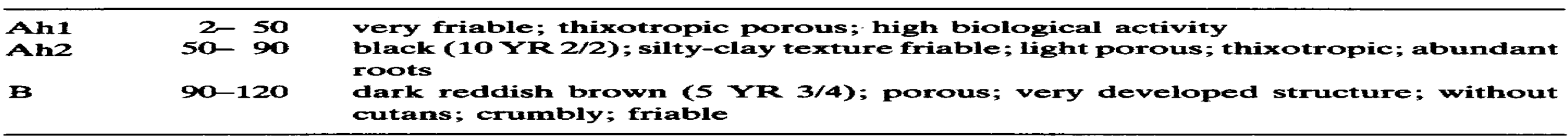




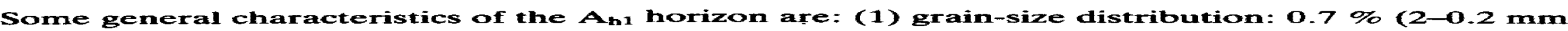

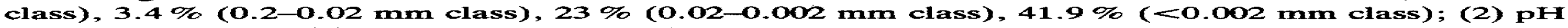
( $\mathrm{I}_{2} \mathrm{O}$ ) $=5.4$; and (3) C-content $=11.3 \%$.

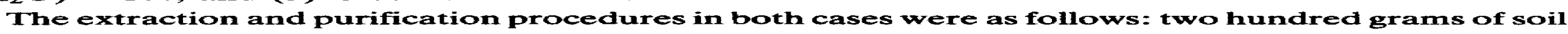

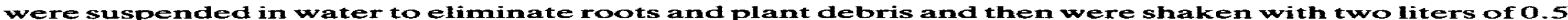

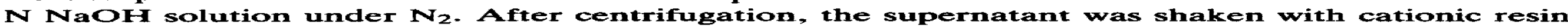

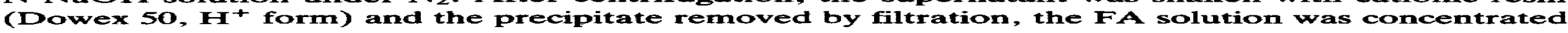
under vacuum, and freeze-dried.

Table 1 shows the ultimate and functional groups analyses of both FA's.

Fable 1 = Elementary analysis (\%) and major oxygen-containing groups (meq/g)

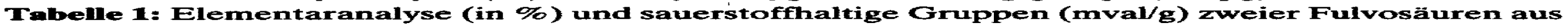
Böden

\begin{tabular}{|c|c|c|c|c|c|c|c|}
\hline Type of fulvic acid & $c$ & $\mathbf{H}$ & $\mathbf{N}$ & $\mathbf{0}$ & Total aciaity & Carboxyl & Hyaroxyl \\
\hline $\begin{array}{l}\text { Humic Haplorthod (FA P) } \\
\text { Andic Hapludult (FA-A) }\end{array}$ & $\begin{array}{l}50.2 \\
40.6\end{array}$ & $\begin{array}{l}4.6 \\
4.1\end{array}$ & $\begin{array}{l}1.8 \\
1.4\end{array}$ & $\begin{array}{l}13-4 \\
53-9\end{array}$ & $\begin{array}{l}12.1 \\
10.2\end{array}$ & $\begin{array}{l}7.9 \\
8.8\end{array}$ & $\begin{array}{l}4.2 \\
1.4\end{array}$ \\
\hline
\end{tabular}

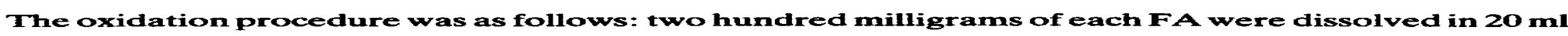

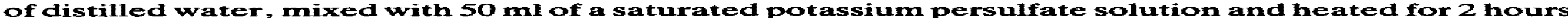

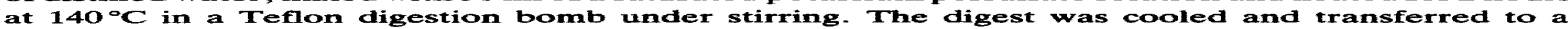

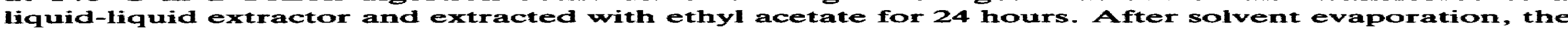

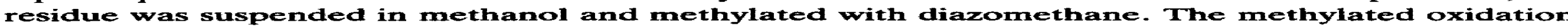

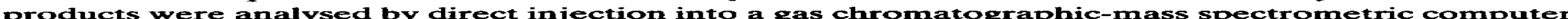

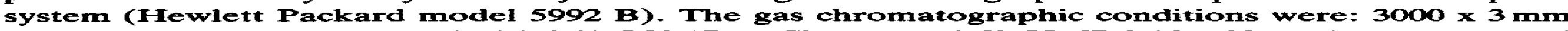

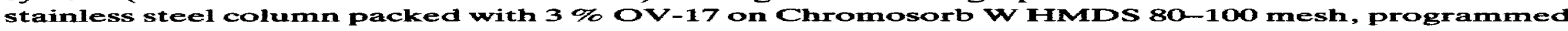

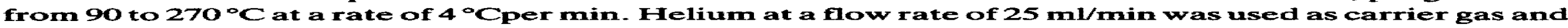
the mass spectrometer was at an ionizing voltage of $70 e V$.

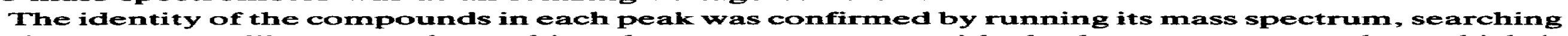

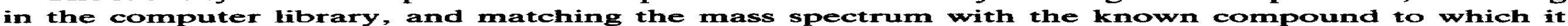

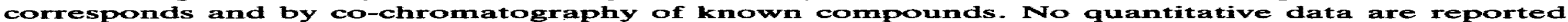

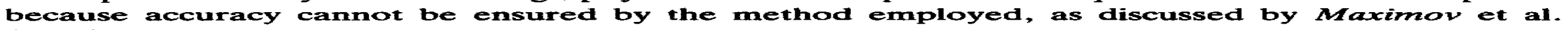
(1977).

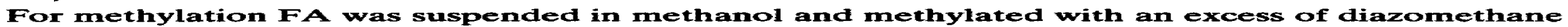
until a constant methoxyl value content had been obtained.

\section{Results and Discussion}

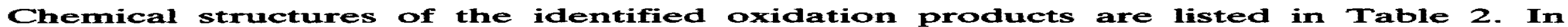

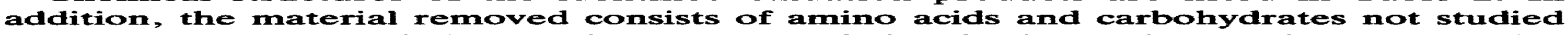

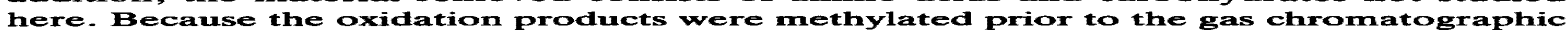

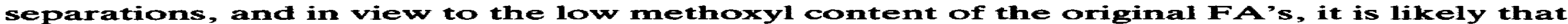

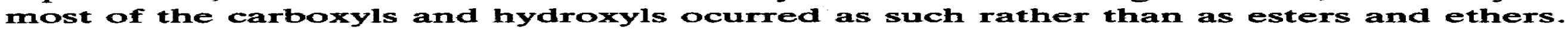


Table 2: Compounds isolated from fulvic acids after persulfate oxidation

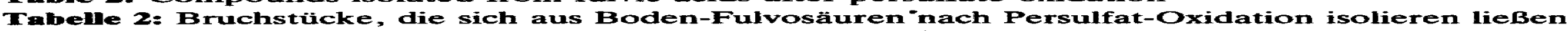
CFA-P: Humic Faplorthod, FA-A: Andic Hapludult, M: methyliert)

\begin{tabular}{|c|c|c|c|c|}
\hline & & $\mathbf{F A}-\mathbf{P}$ & $F A-P M=$ & $\mathbf{F A}-\mathbf{A}$ \\
\hline $\begin{array}{r}1 \\
2 \\
3 \\
4 \\
5 \\
6 \\
7 \\
8 \\
9 \\
10 \\
11 \\
12 \\
13 \\
14 \\
15 \\
16 \\
17 \\
18 \\
19 \\
20 \\
21 \\
22 \\
23 \\
24 \\
25 \\
26 \\
27 \\
28 \\
29 \\
30 \\
31 \\
32 \\
33 \\
34 \\
35 \\
36 \\
37 \\
38\end{array}$ & 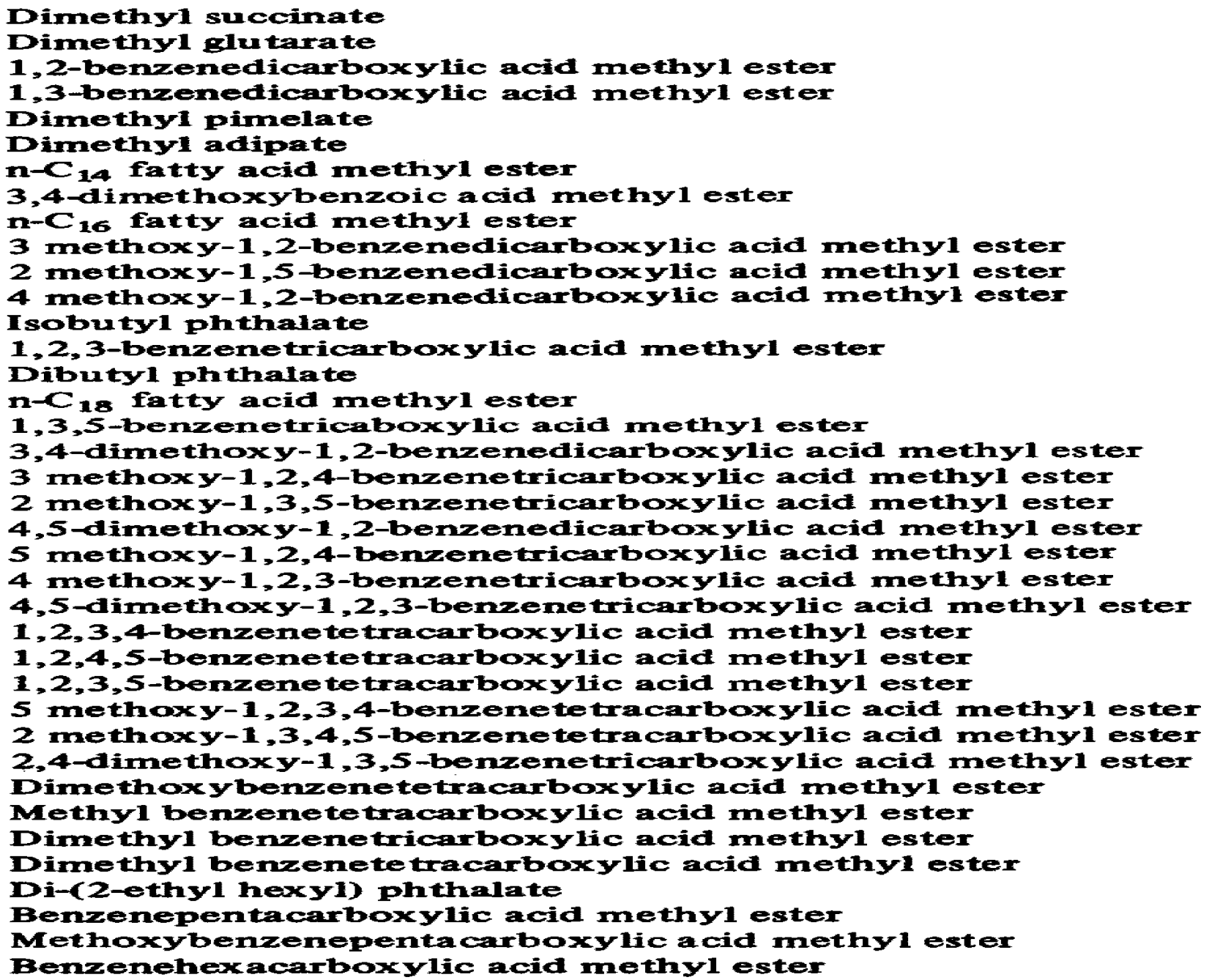 & $\begin{array}{l}++ \\
+ \\
+ \\
+ \\
++ \\
+ \\
++ \\
+ \\
+++ \\
+++ \\
+++ \\
++ \\
+++\end{array}$ & $\begin{array}{l}+ \\
+++ \\
+ \\
+++ \\
+ \\
+ \\
++ \\
+ \\
+++ \\
+ \\
+ \\
+\end{array}$ & $\begin{array}{l}++ \\
+1+ \\
+1+ \\
+-1\end{array}$ \\
\hline
\end{tabular}

* Methylated $\rightarrow+$ medium oontent

$+\quad$ low content $\rightarrow+$ high content 
The most abundant compounds isolated from the oxidation of FA-P, according to the peak height and in decreasing order were the phenolic acids $28,20,19,22$ and 24 , followed by the benzenecarboxylic acids 25,26 and 14 and the fatty acids 9 and 16 . In F A-A and with the same criteria as above, the most abundant compounds were the benzenecarboxylic acids $36,25,26$ and 14 , followed by the fatty acids 9 and 16 and the phenolic acids $28,20,19$ and 23. In the methylated FA-P major compounds were the benzenecarboxylic acids 17 , 14, 25 and 26 followed by the phenolic acids 22,23 and 28 .

No alkanes were detected and methylation prior to oxidation failed to increase the variety and yield of the oxidation products, as shown for IA (Martin et al., 1981). In addition to the above cited compounds some dialkyl phthalates were also identified, and although Matsuda and Schnitzer (1972) have pointed out that humic substances could adsorb large amounts of hydrophobic organic compounds, we assume that in this case they are most likely contaminants introduced in the work up procedure.

The identification of compounds 32,33 and 34 ist tentative though methyl derivatives have been found by Schnitzer (1974) after CuO-NaOH oxidation of a FA. The presence of methyl groups has been explained by Hayes and Swift (1978) by the generation of a carbonyl group on a B-carbon, when the reaction elapse at basic pF. As the persulfate oxidation is at acid pH the above mechanism may not be valid.

Reaction of persulfate with FA is complex and we suggest that the mechanism, as occurs for peracetic acid and potassium permanganate may be an electrophilic attack. Coupling products as reported by Baumgartner (1973) for oxidation of single phenolic compounds were not observed.

To a better understanding of the degradative action of persulfate oxidation, it may be interesting to compare the types of products resulting from the oxidation of FA with different oxidants. Potassium permanganate like peracetic acid at $80^{\circ} \mathrm{C}$ releases as major products benzenecarboxylic acids. Sodium hydroxide, alkaline cupric oxide and peracetic acid at $40^{\circ} \mathrm{C}$ give as major compounds phenolic acid structures (Neyround and Schnitzer, 1977). Most of the compounds listed in Table 2 have been obtained by the above cited degradative methods, but as for HA's (Marin and Gonzalez-Vila, 1981), persulfate differentiate berween FA's formed under widely differing environments. Thus, whereas FA-P gives as major oxidation products phenolic acids, FA-A yields as major compounds benzenecarboxylic acids i.e. while FA-P gives a ratio benzenecarboxylic acids/phenolic acids similar to that formed if alkaline cupric oxide oxidation was used, FA-A gives a value for the above ratio as if potassium permanganate was employed.

The results illustrate the variability of structure of the two FA under study, since the yield of the major types of compounds is different from sample to sample. This finding is in contrast with those reported by Schnitzer,and collaborators who failed to observe any differences in the weight ratios of benzenecarboxylic to phenolic compounds between FA's from different origins.

Recently it has been shown by non-destructive techniques such as ${ }^{13} \mathrm{C}$ NMR that humic materials can be either highly aromatic or aliphatic according to their origin and the precursors from which they are formed (Farcher et al., 1980, Wilson et al ., 1981). In fact, taking into account that the humification process is a complex oxidative degradation 
reaction depending on numerous factors such as climate, vegetation, microbial activity, physico-chemical properties of soil, etc. it is not surprising that the basic chemical structure of the humic substances might be different in every soil. The reason why humic materials from different soils show similar structural characteristics depends probably on the drastic extraction techniques employed, and on the lack of adequate study methods, since spectroscopic techniques have been relatively unsuccessful, while most of the degradative methods alter or destroy the original chemical structure providing a biased information about the chemical make-up of these macromolecules, as have been previously discussed (Maximov et al., 1977, Marcher et al., 1980).

The possibility to differentiate between FA's of different soils, as persulfate does, offers very interesting prospects to the characterization of humic materials.

\section{Referemces}

Baumgartmer, I. (1973): Beitrag zur Oxidation pflanzlicher Phenole insbesondere der Ferulasäure. Thesis E.T.F. Zürich Nr. 4923 Jurin Verlag. Zürich.

Harcher, P.G., Roman, R. and Matingly, MA.A. (1980): IFI and $13 \mathrm{C}$ NMR of marime humic acids. Org- Geochem. $2,77-85$.

Hayes, M.H.B. and Smifi, R.S. (1978)= The chemistry of soil constituents: (Ed. D.J. Greentand and M.F.B. Hayes). John Wiley and Sons, London.

Martin, F. and Gonzalez-Vila, F.J. (1981): L'Oxydation au persulfate des acides humiques du sol. In Colloque Tumus-Azote vol I INRA, Reims PP. 14-18.

Martin, F., Saiz-Jimenez, $C$. and Gonzalez-Vila, F.J. (1981): The persulfate oxidation of a soil humic acids. Soil Sci. 123, $200-203$.

Marsuda, K. and Schnitzer, M. (1972): Reaction between fulvic acid, a humic material and dialkyl phthalates. Bull. Enviromm. Contam Toxicol. 6, 200-203.

Maximov, O.B., Shuets, T.V. and Elkin, Yu.N. (1977): On permanganate oxidation of humic acids. Geoderma 19, 63-78.

Neyroud, $J . A$, and Schmitzer, $M$. (1977): Structure chimique des acides humiques et fulviques du sol. In soil organic matter studies vol 2 , IAEA Vienma PP. $157-169$.

Schnitzer, M. (1974): Alkaline cupric oxide oxidation of a methylated fulvic acid. Soil Biol. Biochem. 6, $1-6$.

Wilson, M.A., Barron, P.F, and Gillam, A.FI (1981): The structure of freshvater humic substances as revealed by ${ }^{13} \mathrm{C}$ NMR spectroscopy - Geochim. Cosmochim. Acta 45, $1743-1750$.

$[P 4167 \mathrm{~B}]$ 